\title{
The Importance of Physical Literacy for Physical Education and Recreation
}

\author{
Umut Davut Basoglu \\ Correspondence: Umut Davut Basoglu, High school of Physical Education and Sports, Nisantasi University, Istanbul, \\ Turkey.
}

Received: February 12, 2018

doi:10.11114/jets.v6i4.3022

\author{
Accepted: March 4, 2018 \\ Online Published: March 18, 2018 \\ URL: https://doi.org/10.11114/jets.v6i4.3022
}

\begin{abstract}
As the basis of characteristics, qualifications, behaviors, awareness, knowledge and understanding of the development of healthy active living and physical recreation opportunities Physical Literacy (PL); has become a global concern in the fields of physical education and recreation since its first use as a term. Experts from different countries and disciplines underline the necessity of expanding the PL context. Despite this international recognition, neither the existence of a work on PL in nor a model of PL in physical education programs has yet to be seen in Turkish literature. The aim of this study is to introduce such an important concept to Turkish literature by a comprehensive literature review and to present the prominence of PL in terms of physical education, physical activity and sports fields. In addition, under the scope of this study, undergraduate and graduate programs in which physical educators are trained to shape both all students and athletes are examined and various proposals are made about how to place PL in these programs. By examining the graduate and postgraduate programs of faculties of sport and physical education and sport sciences in 98 universities in Turkey and NCTR, we come to a conclusion that between the 3.-6. semesters of graduate programs, the introduction of the PL course, training and modules will increase the awareness and competence of the PL. Moreover we expect that it would be beneficial to train these field specialists and bring them to my country through the opening of specific post-graduate training programs in the field of PL.
\end{abstract}

Keywords: physical literacy, physical activity, physical education and sports, recreation

\section{Introduction}

Since its first use as a term, PL has become a global concern in the fields of physical education and recreation. Indeed, physical education programs focus on the development of specific skills by students, the understanding of environment-based action strategies, and the assessment of the effects of physical education on health. As it is clear from this statement, the primary goal of physical education programs is to improve the physical literacy of students (PL) (Sum et. al., 2016). PL, related to the ultimate purpose of a quality physical education or sport program, compose the basis of the characteristics, qualifications, behaviors, awareness, knowledge and understanding of the development of healthy active living and physical recreation opportunities (Tremblay \& Llyod. 2010).

Experts from different countries and disciplines express the necessity of expanding the PL context. At the Developed Western Countries, PL is becoming an important part of physical education, physical activity and sport fields and it is seen that this concept is widely used (Giblin, Dave \& Chris, 2014). In this vein, the United Kingdom, Canada, Australia and New Zealand have recently pioneered major initiatives in education, community and public health to increase participation and performance through PA through PL. (Mandigo vd., 2007). For example, by 2013, the Australian Government has invested A \$200 million to develop and implement programs that encourage the PA. Future savings for health services resulting from the improvement of the population PA in Australia are estimated to be equal to A \$13.8 billion. Considering the prospect of PL at the point of improving PA participation, this crucial thing is to develope an internationally recognized PL model (Allan, Turnnidge \& Côté, 2017). As a matter of fact, the UN Education, Science and Culture Organization; there is a vantage point that a quality physical education is a fundamental part of the school curriculum and vital for both the students and the decision makers responsible for the education of these students (Sum et al., 2016).

Despite this international recognition, neither the existence of a work on PL in nor a model of PL in physical education programs has yet to be seen in Turkish literature. The aim of this study is to introduce such an important concept to 
Turkish literature by a comprehensive literature review and to present the prominence of PL in terms of physical education, physical activity and sports fields. In addition, under the scope of this study, undergraduate and graduate programs in which physical educators are trained to shape both all students and athletes are examined, and recommendations are made on placing PL in these programs.

\subsection{Physical Literacy, Physical Education and Recreation}

Morrison (Mandigo, Francis, Lodewyk, 2007), who puts forward one of the first definitions regarding PL, claims as: "To be physically literate, one should be creative, imaginative, and clear in expressive movement, competent and efficient in utilitarian movement and inventive, versatile, and skillful in objective movement". Following Morrison many similar definitions of physical literacy have been done. For instance Whitehead (2001) defines PL as "disposition acquired by individuals encompassing the motivation, self-confidence, physical competence, knowledge, and understanding that establishes purposeful physical pursuits as an integral element of their lifestyle." In other words an individual who is physically literate can embody the physical nature of movement and can use take the benefit of his/her experiences and knowledge to interact with the environment (Haydn-Davies, 2005).

PL, educates individuals to manage their movements in changing and challenging environmental conditions; about how to maintain their courage, balance, coordination and speed (Mandigo \& Holt, 2004). PL; forms the basis for characteristics, qualifications, behaviors, awareness, knowledge and understanding of the development of healthy active living and physical recreation opportunities (Gabbani, 2001). According to Lloyd et al., (2012) PL have four inter-related core domains: (a) physical fitness (cardio-respiratory, muscular strength and flexibility), (b) motor behavior (fundamental motor skill proficiency), (c) physical activity behaviors (directly measured daily activity), and (d) psycho-social/cognitive factors (attitudes, knowledge, and feelings). In this vein Corbin (2016) states that physical literacy provides a foundation for elite sport, public health, recreation and physical education rather than merely being a term used to improve public perceptions.

Penney and Chandler (2000), point out that physical education is not just limited to teaching only certain physical activities (PA); it also includes the acquisition of certain skills and competencies through PAs. Particularly in the modern world where physical movements are increasingly restricted and obesity spreads even among children (Drummy et al., 2014); the movement capacities that address deep and meaningful ways of learning physical skills are ignored. In Western Countries approximately $20 \%$ of four to five year old children are reported to be overweight or even obese. According to the Health Survey conducted on Northern Ireland in 2011, around a quarter of 2-15 year old children were evaluated as either overweight or obese either. Childhood obesity may lead to in many health problems and enhances the risk of obesity in older ages (Reilly et al, 2003). So PL is perhaps the type of education that should be provided at pre-primary level in physical education (Giblin, Dave \& Chris, 2014).

Physical literacy is the basis of skills or tools -social/cognitive, behavioral, and fitness related - that students need to acquire or extend with the aim of taking a part in physical activity and sport for lifetime enjoyment and success (Lloyd et al., 2012; Lloyd \& Tremblay, 2010). Within PL education, students gain four basic areas of mobility, in terms of agility, balance, coordination and speed. Moreover PL is concerned with determining the needs of the students, their activities and sports branches, and their predisposition by recognizing the rich recreational activities and sports branches of the students. Skills such as running, jumping, swimming, slipping and cycling are gained to students within the scope of PL. Objects are also required for sports skills such as tennis, table tennis and jockey based on throwing and holding (Hinkley et al, 2008). At this point, the PL emerges as the main content of physical education courses and programs, although it is not mentioned namely in current programs. Students with PL will have high levels of self-confidence as they are aware of their physical abilities as well as their basic mobility skills. Therefore, it is an imperative for physical education courses and programs to focus on PL concept.

\subsection{PL at Physical Education and Sport Programs Curriculum}

Although it is a necessity for physical education courses and programs to focus on the concept of PL, it is not yet possible to find a model of PL in university programs that educate physical education and sports teachers, coaches, recreation specialists and sports managers in Turkey. This section examines the graduate and postgraduate programs in which physical educators are trained to shape both all students and athletes. Moreover in this section we also discuss how to incorporate PL into these programs. 
Table 1. Evaluation of Existing Curriculums in Physical Education and Sports Programs

\begin{tabular}{|c|c|c|c|c|c|}
\hline Semester & Course & $\begin{array}{l}\text { In How Many } \\
\text { Universities? }\end{array}$ & Semester & Course & $\begin{array}{c}\text { In How Many } \\
\text { Universities? }\end{array}$ \\
\hline \multirow{4}{*}{ 1.Semester } & $\begin{array}{l}\text { Introduction to Sports } \\
\text { Sciences }\end{array}$ & 97 & \multirow{3}{*}{$\begin{array}{c}5 . \\
\text { Semester }\end{array}$} & Sports Pedagogy & 65 \\
\hline & Anatomy & 93 & & $\begin{array}{l}\text { Physical relevance in } \\
\text { Training Sciences }\end{array}$ & 45 \\
\hline & General Gymnastics & 82 & & $\begin{array}{l}\text { Social Responsibility } \\
\text { Projects and Practices }\end{array}$ & 52 \\
\hline & Kinesiology & 87 & \multirow{3}{*}{$\begin{array}{c}6 . \\
\text { Semester }\end{array}$} & $\begin{array}{c}\text { Effective Communication } \\
\text { Skills }\end{array}$ & 41 \\
\hline \multirow[t]{2}{*}{ 2. Semester } & $\begin{array}{l}\text { Exercise and Sports } \\
\text { Physiology }\end{array}$ & 78 & & Recreation Practices & 58 \\
\hline & Athletics & 71 & & $\begin{array}{l}\text { Special Education } \\
\text { Methodologies }\end{array}$ & 46 \\
\hline \multirow{3}{*}{ 3. Semester } & Sports Biomechanics & 77 & \multirow{3}{*}{$\begin{array}{c}7 . \\
\text { Semester }\end{array}$} & $\begin{array}{l}\text { Management and } \\
\text { Organization in Sports }\end{array}$ & 55 \\
\hline & $\begin{array}{l}\text { Psychomotor } \\
\text { Development }\end{array}$ & 82 & & Sports Psychology & 64 \\
\hline & Swimming & 65 & & Sports Animation & 32 \\
\hline \multirow{3}{*}{ 4. Semester } & $\begin{array}{l}\text { Sports Movement and } \\
\text { Skill Learning }\end{array}$ & 52 & \multirow{3}{*}{$\begin{array}{c}8 . \\
\text { Semester }\end{array}$} & Sports in Disabilities & 40 \\
\hline & General Gymnastics & 65 & & Educational Games & 36 \\
\hline & Sports Pedagogy & 52 & & $\begin{array}{c}\text { Rhythm Education and } \\
\text { Dance }\end{array}$ & 59 \\
\hline
\end{tabular}

As seen in Table 1, we have examined the curriculums of Physical Education and Sports Schools or Sports Sciences Faculties in Turkey. We find that the most common lessons are as follows; General Gymnastics, Athletics, Swimming, Sports Movement and Skill Learning, Sports Pedagogy, Recreation Practices, Kinesiology, Educational Games, Rhythm Education and Dance, Sports Psychology. We come to a conclusion that the courses that even though those courses can not fully meet the PL as the content, they are quite related to the FOY. In this context, we believe that integrating PL between 3-6 semesters of the curriculums of Physical Education and Sport Schools or Sports Sciences Faculties can be very useful.

\section{Conclusion}

Recent studies suggest that physical education curriculum should involve a physical literacy approach as well as fundamental movement skills. Thus Physical literacy is a considerably important goal of physical education. Developing an understanding towards physical literacy would shed light on the special nature of physical education. This is neither not relevant specifically to teaching children and young people to play sports; nor is it simply about finding those with the competency to become elite athletes. Physical education is about supporting every child, student, young person, and citizen to become a lifetime participant in PA. Particularly with the widespread use of technology, the need for human power is diminishing day by day. This immobile or less mobile life has influences on social life and health of the human beings. Especially children in school age; is grown with technological devices at home and at the hands of the computer, with almost no physical movement. For this reason, the likelihood of obesity in children is increasing. Knowing and teaching physical literacy in primary education, even in kindergarten, is becoming a necessity.

Athletic training, as well as discovering athletical skills begins at an early age. How small are the athletes around the world in the Olympics? Why can not Turkey acheive success? In order to find answers to those questions, we may need to keep an eye on Turkish education system. For example, look at the curriculum of primary teachers in universities; According to, the first ten universities, according to the URAP (University Ranking by Academic Performance) university rankings in 2017 -such as Istanbul University, Hacettepe University, Ankara University, Gazi University- do not include "physical literacy" in their training modules (URAP, 2017). There are only "Physical Education and Sports Culture" and "Physical Education and Game Teaching" courses in the classroom teacher curriculum at Istanbul University, Hacettepe University, Ankara University and Gazi University. In order to overcome this deficiency, we think that it is important to add the curriculum of "Physical Literacy" course in primary education programs and even kindergarten education programs. In addition, the number of academics, coaches, who will be able to teach the Physical Literacy course to be placed in the course curriculum is far from being enough. We expect that that teaching PL at the university period will provide important contributions to the concepts of sports and egsersize in the future periods.

As a result of examining the graduate and postgraduate programs of faculties of sport and physical education and sport sciences in 98 universities in Turkey and NCTR, we could not find a course, a module o practice titled as PL. However even the existing courses can not fully meet the PL as the content, they are quite related to PL. We expect that the 
introduction of PL courses trainings and modules, particularly between 3-6 semesters at the curriculums of Physical Education and Sport Schools or Sports Sciences Faculties to increase the awareness and competence of the PL. Moreover we expect that it would be beneficial to train these field specialists through the opening of specific post-graduate training programs in the field of PL.

\section{References}

Allan, V., Turnnidge, J., \& Côté, J. (2017). Evaluating Approaches to Physical Literacy Through the Lens of Positive Youth Development. Quest, 1-16. https://doi.org/10.1080/00336297.2017.1320294

Corbin, C. B. (2016). Implications of physical literacy for research and practice: A Commentary. Research quarterly for exercise and sport, 87(1), 14-27. https://doi.org/10.1080/02701367.2016.1124722

Drummy, C., Breslin, G., Davison, G. W., McKee, D., Murphy, M. H. (2014). Correlates of Pedometer determined physical activity in 4-5 year old children. Journal of Sport and Health Research, 6(1), 75-86.

Gabbani, F. (2001). Physical education-physical literacy kinesthetic intelligence. Physical \& Health Education Journal, $67(1), 2$.

Giblin, S., Dave, C., \& Chris, B. (2014). Physical literacy: importance, assessment and future directions. Sports Medicine, 44(9), 1177-1184. https://doi.org/10.1007/s40279-014-0205-7

Gutin, B., Yin, Z., Humphries, M. C., \& Barbeau, P. (2005). Relations of moderate and vigorous physical activity to fitness and fatness in adolescents. The American journal of clinical nutrition, 81(4), 746-750. https://doi.org/10.1093/ajcn/81.4.746

Haydn-Davies, D. (2005). How does the concept of Physical Literacy relate to what is and what could be the practice of Physical Education? British Journal of Teaching Physical Education, 36(3), 45-48.

Lloyd, R. S., Oliver, J. L., Meyers, R. W., Moody, J. A., \& Stone, M. H. (2012). Long-term athletic development and its application to youth weightlifting. Strength \& Conditioning Journal, 34(4), 55-66. https://doi.org/10.1519/SSC.0b013e31825ab4bb

Mandigo, J. L., \& Holt, N. L. (2004). Reading the game. Introducing the notion of games literacy. Physical and Health Education Journal, 70(3), 4-10.

Mandigo, J., Francis, N., \& Lodewyk, K. (2007). Physical literacy concept paper. Canadian Sport for Life.

Penney, D., \& Chandler, T. (2000). Physical education: What future (s)?. Sport, Education and Society, 5(1), 71-87. https://doi.org/10.1080/135733200114442

Reilly, J. J., Methven, E., McDowell, Z. C., Hacking, B., Alexander, D., Stewart, L., \& Kelnar, C. J. (2003). Health consequences of obesity. Archives of disease in childhood, 88(9), 748-752. https://doi.org/10.1136/adc.88.9.748

Sum, R. K. W., Ha, A. S. C., Cheng, C. F., Chung, P. K., Yiu, K. T. C., Kuo, C. C. (2016). Construction and Validation of a Perceived Physical Literacy Instrument for Physical Education Teachers. PLoS ONE, 11(5), e0155610. https://doi.org/10.1371/journal.pone.0155610

Tremblay, M., \& Llyod, M. (2010). Physical Literacy Measurement The Missing Piece. Physical \& Health Education Journal, 76(1), 13-25.

Whitehead, M. (2001). The concept of physical literacy. European Journal of Physical Education, 6, 127-138. https://doi.org/10.1080/1740898010060205

\section{Copyrights}

Copyright for this article is retained by the author(s), with first publication rights granted to the journal.

This is an open-access article distributed under the terms and conditions of the Creative Commons Attribution license which permits unrestricted use, distribution, and reproduction in any medium, provided the original work is properly cited. 